\title{
Efforts To Reduce Downgrade Of Steel Pipes In The Production Process Using The HEART Method
}

\section{Upaya Mengurangi Downgrade Pipa Baja Pada Proses Produksi Menggunakan Metode HEART}

\author{
Irfan Widya Julianto ${ }^{1}$, Hana Catur Wahyuni ${ }^{2}$ \\ \{irfanwidya99@gmail.com ${ }^{1}$, hanacatur@umsida.ac.id $\left.{ }^{2}\right\}$
}

Program Studi Teknik industri, Fakultas Sains dan teknologi, Universitas Muhammadiyah Sidoarjo ${ }^{1,2}$

\begin{abstract}
Pt X is a company that produces steel pipe of various shapes and size. In the production procces not only using machines but also using humans as operators. So in this case humans play an important role in maintaining the quality of production. The purpose of this study is to analyze the human error probability with Human Error Assessment and Reduction Technique method (HEART). HEART is a method designed as a fast and simple human reliability assessment in quantifying the risk of human error. From this research, it was found that 3 tasks had a high HEP value which caused the decline in pipe quality during the production process, namely task 3.2, 4.1 and task 3.4. Which has the highest HEP value on task 3.2, namely setting the machine with a value of 0,7680. The cause is due to the lack of operator expertice and the center roll was not carried out when installing it, so that training is needed to increase operator expertice.
\end{abstract}

Keywords - human error probability; kualitas

\begin{abstract}
Abstrak. PT. X merupakan perusahaan yang memproduksi pipa baja berbagai bentuk dan ukuran. Dalam proses produksinya tidak hanya mengandalkan mesin tetapi juga manusianya sebagai operator produksi. Dalam hal ini manusia memiliki peran penting dalam menentukan kualitas. Tujuan dari penelitian ini yaitu menganalisis nilai human error probability (HEP) dengan menggunakan metode Human Error Assessment and Reduction Technique (HEART). HEART merupakan metode yang dirancang sebagai Human Reliability Assesment (HRA) yang cepat dan sederhana dalam menguantifikasi resiko human error. Dari hasil penelitian ini didapat 3 task yang mempunyai nilai HEP tinggi yang menjadi penyebab terjadinya downgrade kualitas pipa saat proses produksi yaitu task 3.2, 4.1 dan task 3.4 . Dari ketiga task tersebut yang memiliki nilai HEP tertinggi yaitu pada task 3.2 pada aktivitas penyetingan mesin dengan nilai HEP 0,7680 yang disebabkan kurangnya kemampuan dari operator dan tidak dilakukannya center dan level roll pada saat proses pemasangan awal, sehingga perlu dilakukan pelatihan untuk meningkatkan keahlian dari operator mesin.
\end{abstract}

Kata Kunci - human error probability; kualitas

\section{PENDAHULUAN}

Semakin berkembangnya teknologi dan bertambahnya perusahaan - perusahaan baru yang muncul, maka persaingan antar perusahaan akan meningkat. Sehingga perusahaan harus lebih meningkatkan kualitas hasil produksi secara berkala dan memperbaiki kekurangan pada proses agar menghasilkan produk yang berkualitas baik sehingga dapat bersaing dipasar dan mendapat kepercayaan konsumen[1]. Dalam suatu proses produksi kemungkinan terjadinya suatu masalah dan kendala yang menyebabkan kegagalan produk pasti ada meskipun prosesnya sudah direncanakan dan dilakukan dengan baik. Pada proses produksi manusia sebagai operator sangat berpengaruh terhadap kualitas hasil produksi bukan hanya dari faktor material dan mesin saja. Dalam hal ini manusia memiliki peran penting dalam menjaga kualitas, dimana manusialah yang mengendalikan jalannya proses produksi. Karena manusia memiliki keterbatasan, sehingga dalam menjalankan proses produksi akan berpotensi melakukan kesalahan atau human error yang berdampak pada kualitas produk yang dihasilkan[2].

Permasalahan yang saat ini terjadi pada proses produksi adalah peningkatan downgrade produk yang terbilang tinggi yaitu rata - rata sebesar 425 batang pipa downgrade dan sebesar 431 pipa BS atau 1,38 \% perharinya, presentase downgrade tersebut cukup tinggi sehingga perlu diturunkan. Untuk mengurangi peningkatan downgrade produk yang disebabkan kesalahan kerja perlu dilakukan pengukuran keandalan manusia (human reliability). Berdasarkan hal tersebut maka penelitian ini akan meneliti masalah-masalah yang menyebabkan terjadinya human error pada proses produksi. 


\section{Pengendalian Kualitas}

Pengendalian kualitas dilakukan untuk menghasilkan suatu produk barang maupun jasa dengan kriteria yang diinginkan dan direncanakan oleh perusahaan[3]. Tujuan dari dilakukannya pengendalian kualitas adalah: [4]

1. Agar barang yang telah di produksi mencapai standar kualitas yang ditetapkan

2. Mengusahakan biaya pemeriksaan atau perbaikan sekecil mungkin

3. Untuk bisa mendapatkan jaminan kualitas, bahwa kualitas yang diproduksi sesuai dengan ketentuan yang telah ditetapkan

\section{Definisi Human Error}

Human error adalah keputusan atau perilaku manusia yang tidak tepat atau berpotensi mengurangi efektivitas, keselamatan atau performa sistem[5]. Human error merupakan salah satu penyebab penurunan kualitas produk. Tinjauan tentang human error sebagai penyebab kegagalan produk dalam proses manufaktur menyebutkan adanya signifikansi kesalahan manusia sebagai penyebab permasalahan kualitas di beberapa industri manufaktur Klasifikasi human error adalah sebagai berikut: [6]

a. Error of Omission merupakan kesalahan yang disebabkan karena kurangnya tahap dalam suatu proses.

b. Error of Commission yaitu ketika mengerjakan sesuatu tetapi dengan cara yang salah dan tidak sesuai prosedur kerja.

c. A Sequence Error merupakan kesalahan saat melakukan pekerjaan tidak sesuai dengan urutan yang seharusnya.

Human Error dapat digolongkan ke dalam banyak kategori seperti berikut:

a. Proses operasi error merupakan kesalahan yang dilakukan operator pada waktu proses produksi yang disebabkan beberapa penyebab seperti faktor lingkungan yang buruk, kecerobohan terhadap pekerjaan yang dilakukan, beban kerja yang berlebihan, dll.

b. Desain error merupakan kesalahan dalam proses perancangan bentuk dan fungsi yang tidak sesuai dengan kebutuhan yang disebabkan karena kurangnya perhitungan dalam mendesain, waktu yang terlalu singkat dan kurang telitinya dalam mendesain.

c. Instalasi error yaitu kesalahan yang terjadi saat proses instalasi peralatan yang tidak sesuai dengan instruksi.

d. Inspeksi error merupakan kurang akuratnya proses pengecekan sehingga menimbulkan kecacatan dan kesalahan yang lebih besar.

e. Perawatan error merupakan kurang tepatnya operator dalam melakukan perawatan dan perbaikan sehingga tidak berfungsi dengan seharusnya.

f. Assembly error merupakan kesalahan yang terjadi karena kurangnya keahlian yang dimiliki operator ,kurangnya ketelitian dalan melakukan perakitan.

Salah satu metode yang dapat digunakan untuk menghitung nilai probabilitas kesalahan manusia dalam melakukan suatu aktivitas adalah metode HEART (Human Error Assessment and Reduction Technique). Metode HEART dirancangg untuk menjadi metode yang cepat dan sederhana dalam mengkuantifikasikan risiko kesalahan manusia yang berlaku secara umum di setiap industri yang mengutamakan reliabilitas manusia[7].

HEART adalah teknik yang digunakan dalam bidang human reliability assessment (HRA) dengan menggunakan salah satu metode kuantifikasi yang bertujuan ntuk memberikan penilaian probabilitas human error dengan menerjemahkannya dalam generic categories dan error producing conditions (EPCs) untuk keperluan mengevaluasi kemungkinan kesalahan manusia yang terjadi selama penyelesaian tugas tertentu[8]. Oleh karena itu, metode ini bisa digunakan untuk menghitung human error proses produksi yang membutuhkan tingkat pengawasan dan ketelitian yang tinggi[9]. Kelemahan dari metode HEART yaitu bersifat subjektif sehingga hasil yang diperoleh antara peneliti satu dengan yang lain belum tentu sama[10].

\section{METODE}

Pengumpulan data diperoleh dari dua tahap, yang pertama adalah tahap observasi yang dilakukan dengan cara pengamatan proses produksi dilapangan secara langsung, dari proses pemotongan bahan baku sampai proses packing. Dan yang kedua melalui wawancara kepada pihak yang terkait dalam proses produksi secara langsung di lapangan. Kemudian dilakukan langkah - langkah dalam menghitung nilai HEP dengan menggunakan metode HEART yaitu

1.Mengidentifikasi seluruh daftar pekerjaan apa saja yang dilakukan karyawan saat proses produksi pembuatan pipa baja dari awal sampai akhir .

2.Mengkategorikan setiap pekerjaan yang dilakukan sesuai dengan tabel Generic Task Type (GTT) untuk memperoleh nilai Human Unrealibility.

3.Menentukan nilai EPCs / max effect dengan cara mengelompokkan faktor - faktor yang dapat menyebabkan terjadinya error.

4.Menentukan nilai Assessed Proportion of Effect (APOE) antara 0 sampai 1. Semakin tinggi nilai proporsinya semakin berpengaruh terhadap terjadinya kesalahan. 
Procedia of Engineering and Life Science Vol. 1. No. 2 Juni 2021

Seminar Nasional \& Call Paper Fakultas Sains dan Teknologi (SENASAINS 2nd)

Universitas Muhammadiyah Sidoarjo

5.Menghitung nilai Assessed Effect dengan rumus (( EPC - 1) x APOE ) + 1)

6.Selanjutnya menghitung nilai Human Error Probability dengan cara mengalikan nilai Human Unrealibility dengan nilai Assessed Effect.

Setelah diketahui aktifitas yang mempunyai nilai HEP yang tinggi kemudian dilakukan analisa untuk menentukan rekomendasi perbaikan.

\section{HASIL DAN PEMBAHASAN}

Perhitungan ini dilakukan untuk mendapatkan nilai Human Error Probability (HEP) pada setiap aktifitas yang dilakukan selama proses produksi. Dengan demikian akan diketahui aktifitas yang memiliki resiko paling tinggi terjadinya kesalahan manusia yang selanjutnya akan dilakukan langkah - langkah perbaikan untuk mengurangi terjadinya kesalahan. Hasil perhitungan nilai HEP dengan menggunakan metode HEART pada proses produksi dapat dilihat pada tabel 1.

Tabel 1 nilai Human Error Probability

\begin{tabular}{|c|l|c|}
\hline $\begin{array}{c}\text { Kode } \\
\text { Task }\end{array}$ & \multicolumn{1}{|c|}{ Task } & HEP \\
\hline 1.1 & Memeriksa Spesifikasi Coil & 0,0212 \\
1.2 & Pemotongan Coil & 0,3942 \\
1.3 & Memberikan Identitas Strip & 0,0330 \\
1.4 & Memindah Strip Ke mesin Penyambungan & 0,2016 \\
2.1 & Pengecekan Identitas Strip & 0,0231 \\
2.2 & Penyambungan Strip & 0,0360 \\
2.3 & Pengisian Accumulator & 0,4464 \\
3.1 & Pengecekan Roll, Stand, dan Bearing & 0,4896 \\
3.2 & Penyetingan Mesin & 0,7680 \\
3.3 & Penyesuaian Temperatur Welding & 0,2160 \\
3.4 & Pengontrolan Mesin & 0,5328 \\
4.1 & Pengecekan kualitas Pipa Baja & 0,5760 \\
4.2 & Packing Pipa & 0,1483 \\
4.3 & Pemindahan Pipa Ke Gudang Penyimpanan & 0,3600 \\
\hline
\end{tabular}

Dari tabel 1 dapat dilihat bahwa ada 14 aktifitas yang ada pada proses produksi dengan nilai human error yang terendah dengan nilai 0,0212 dan tertinggi 0,7680 . Untuk lebih jelasnya urutan nilai HEP dari yang tertinggi dapat dilihat pada gambar 1 .

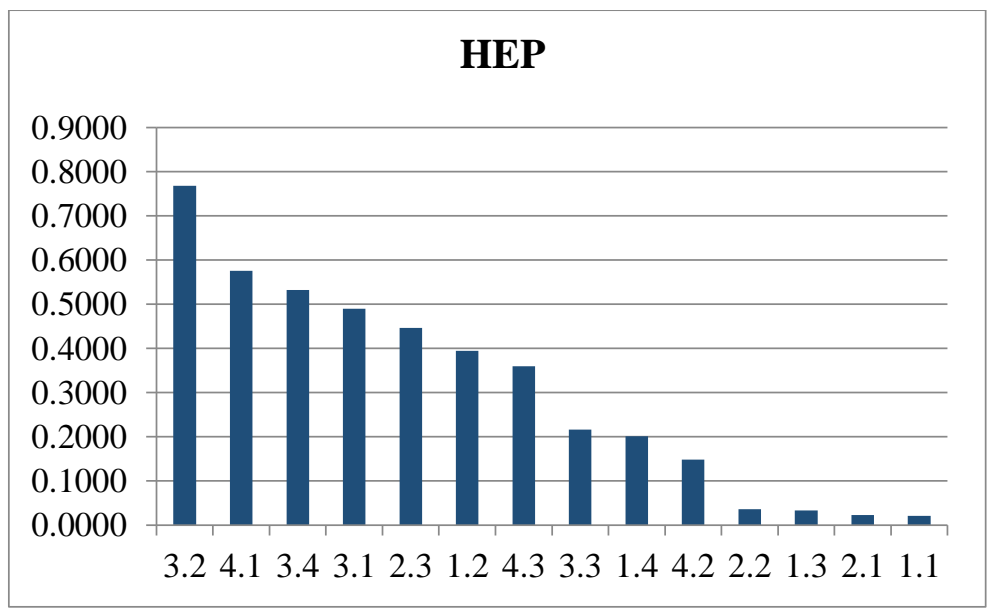

Gambar 1 Diagram nilai HEP proses produksi di PT SPINDO

Dari gambar 1 dapat dilihat bahwa Ada tiga task yang memiliki nilai HEP diatas 0,5 yaitu pada task 3.2 penyetingan mesin dan task 3.4 pengontrolan mesin merupakan aktivitas yang ada pada bagian mesin pembentukan pipa, sedangkan task 4.1 pengecekan kualitas pipa baja merupakan aktivitas pada bagian packing. Upaya yang perlu 
Procedia of Engineering and Life Science Vol. 1. No. 2 Juni 2021

Seminar Nasional \& Call Paper Fakultas Sains dan Teknologi (SENASAINS 2nd)

Universitas Muhammadiyah Sidoarjo

dilakukan untuk mengurangi downgrade pipa baja yaitu dengan cara meminimkan terjadinya human error pada bagian tersebut. Untuk menentukan penyebab masalah pada penelitian ini menggunakan diagram fishbone yang dapat dilihat pada gambar 2 sampai 4

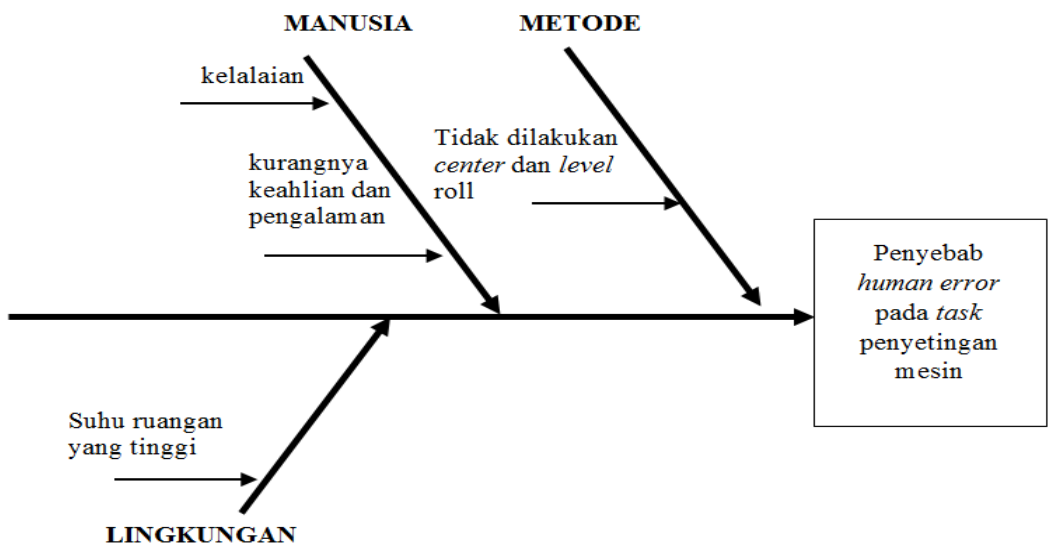

Gambar 2 Diagram fishbone penyebab human error pada bagian penyetingan mesin

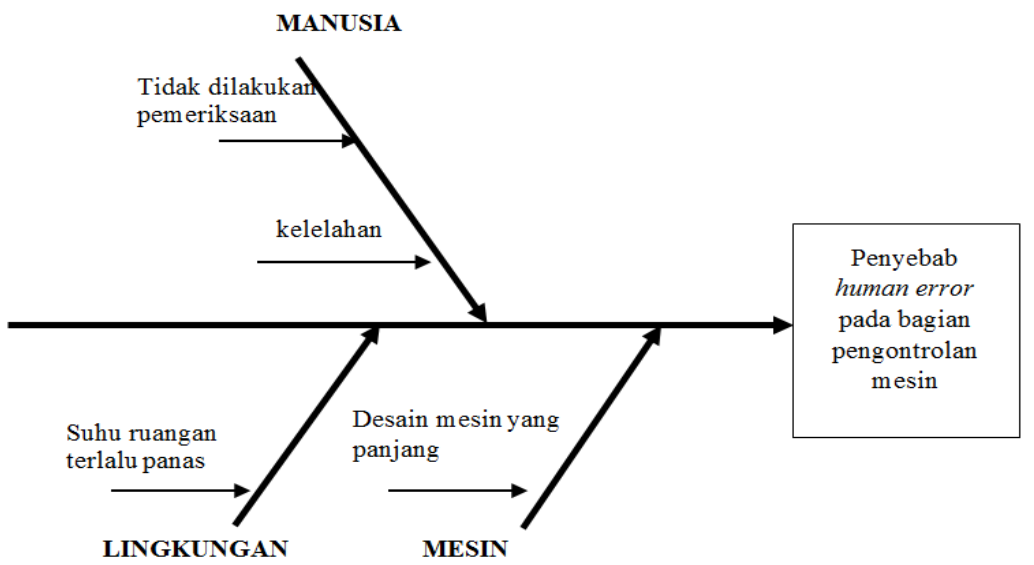

Gambar 3 Diagram fishbone penyebab human error pada task pengontrolan mesin

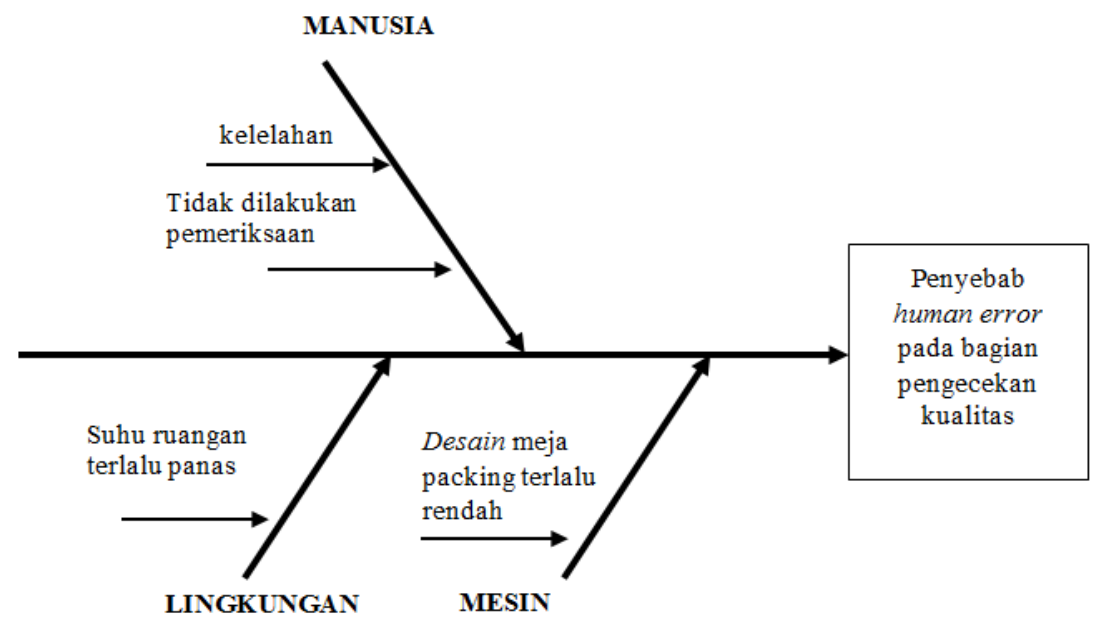

Gambar 4 Diagram fishbone penyebab human error pada bagian pengecekan kualitas pipa baja

Pada aktivitas penyetingan mesin ini merupakan proses yang rumit sehingga menjadi penyebab utama terjadinya down grade pipa baja, dalam hal ini keandalan dan pengalaman operator sangat dibutuhkan dalam penyetingan mesin dan perlu dilakukan center dan level roll pada saat pemasangan awal roll. Kemudian pada task kode 4.1 yaitu aktivitas pengecekan kualitas pipa dengan nilai HEP sebesar 0,5760. Hal ini terjadi karena faktor kelelahan 
karyawan sehingga kurangnya pengontrolan kualitas pipa bahkan tidak dilakukannya pengontrolan pada saat proses produksi sedang berlangsung. Kemudian yang ketiga pada task kode 3.4 yaitu pengontrolan mesin dengan nilai HEP 0,5328. Hal ini terjadi karena kurangnya pengalaman operator, banyaknya aktivitas yang dilakukan operator dan dimensi mesin yang panjang sehingga menyebabkan pengawasan mesin yang kurang optimal.

\section{Rekomendasi Perbaikan}

Setelah diperoleh nilai HEP dan diketahui penyebab masalah dari terjadinya kesalahan manusia peneliti memberikan saran perbaikan agar dapat meminimalkan terjadinya human error pada proses produksi sehingga dapat mengurangi downgrade pipa baja di PT X

1. Task Penyetingan Mesin

Pada proses penyetingan mesin ini memiliki nilai HEP tertinggi yaitu sebesar 0,7680. Dalam penyetingan mesin diperlukan pengalaman dan kemampuan yang tinggi dari operator mesin mill karena karakter ditiap mesin yang berbeda sehingga dalam penempatan operator mesin seharusnya tidak diganti - ganti. Rencana perbaikan dari Beberapa kesalahan yang dilakukan operator mesin mill yang dapat mempengaruhi kesuksesan dalam penyetingan mesin yaitu:

- Diadakan pelatihan operator mesin untuk meningkatkan keahlian operator dan mengadakan koordinasi antar shift tentang masalah dan kendala yang ditumui sehingga dapat meningkatkan pengetahuan dan keterampilan operator[11].

- Melakukan center dan level roll pada waktu pemasangan roll awal saat ganti ukuran pipa, Dengan dilakukan center dan level roll posisi pita strip akan terbentuk sesuai dengan bentuk roll sehingga mempermudah proses penyetingan mesin. Karena posisi roll yang tidak center dan level akan menyebabkan terjadinya tekanan berlebihan dan tidak sesuai dengan desain roll sehingga menyebabkan tepi strip bergelombang, pipa mluntir, dan tidak stabilnya proses pengelasan pipa.

\section{Pengecekan kualitas pipa}

Dalam proses produksi yang memiliki nilai HEP besar kedua yaitu sebesar 0,5760 pada proses pengecekan pipa baja yang dilakukan pada bagian packing. Pada proses pengecekan pipa ini kurang optimal karena sering kali terjadi kelolosan yang disebabkan kelebihan beban kerja dan faktor kelelahan. Rencana perbaikan yang dilakukan untuk mengoptimalkan pengecekan pipa yaitu:

- Melakukan pengecekan pipa sesering mungkin.

- Meja packing terlalu rendah yang menyebabkan posisi kerja membungkuk pada saat packing pipa. Sehingga perlu dilakukan perbaikan posisi meja packing yang bisa disesuaikan, agar beban kerja karyawan lebih rendah dan tidak cepat mengalami kelelahan.

- Suhu udara yang tinggi dapat menimbulkan kelelahan dan menurunnya konsentrasi yang cenderung menimbulkan kesalahan[2], sehingga perlu di lakukan perbaikan suhu udara seperti penambahan kipas angin.

3. Pengontrolan Mesin

Berdasarkan perhitungan dengan metode HEART pada task pengontrolan mesin mill nilai HEP sebesar 0,5130 yang dinilai cukup besar.

Rencana perbaikan untuk mengurangi terjadinya pipa cacat pada saat mesin beroperasi adalah

- Operator lebih Meningkatkan frekuensi pengontrolan mesin agar pada saat mesin mengalami masalah dapat segera diketahui untuk menghindari banyaknya jumlah pipa cacat karena mesin terus beroperasi.

- Perlu diberikan pelatihan agar operator lebih peka terhadap hal-hal yang menjadi tanda atau gejala terjadinya masalah pada saat mesin beroperasi, seperti putaran roll yang goyang dan tidak lancar yang menandakan bearing sudah aus atau pecah sehingga perlu diganti.

\section{KESIMPULAN}

Dari hasil perhitungan nilai Human Error Probability menggunakan metode HEART diketahui aktifitas yang memiliki resiko paling tinggi terjadinya kesalahan manusia adalah pada proses penyetingan mesin dengan nilai HEP sebesar 0,7680, kesalahan ini disebabkan karena kurangnya keandalan operator dimana pada proses penyetingan mesin diperlukan pengalaman dan kemampuan yang tinggi dari operator mesin dan penyebab yang kedua yaitu tidak dilakukannya center dan level roll pada waktu proses pemasangan roll awal, sehingga menyebabkan terjadinya kesalahan - kesalahan dalam proses penyetingan menjadi lebih tinggi. Pada aktifitas pengecekan pipa memiliki nilai HEP sebesar 0,5760 yang disebabkan karena faktor kelelahan sehingga proses pengecekan pipa tidak optimal. Pada aktifitas pengontrolan mesin nilai HEP sebesar 0,5130 yang disebabkan karena kurangnya pengalaman dari operator dan desain mesin yang panjang.

Dan selanjutnya perlu dilakukan penelitian pada bagian warehouse dan delivery untuk menggetahui aktivitas yang memiliki nilai HEP tinggi dikarenakan pada bagian tersebut juga sering terjadinya downgrade pipa sehingga menyebabkan terjadi komplain oleh customer. 


\section{UCAPAN TERIMA KASIH}

Dengan memanjatkan puji syukur kehadirat Tuhan Yang Maha Esa yang telah memberikan rahmat, taufik dan hidayahnya sehingga dapat menyelesaikan penelitian dengan judul "Upaya Mengurangi Downgrade Pipa Baja Pada Proses Produksi Menggunakan Metode HEART". Penelitian ini tidak akan terwujud tanpa ridho Allah SWT serta bantuan dari pihak yang telah membantu selama penelitian dan pada kesempatan ini saya ingin mengucapkan terima kasih kepada pihak perusahaan PT. X yang telah memberi ijin dilakukannya penelitian di area produksi dan kepada kasie serta karyawan yang ada dibagian produksi. Semoga hasil penelitian ini dapat digunakan sebagai bahan pertimbangan bagi perusahaan.

\section{REFERENSI}

[1] Khoirunnisa; Gerry Ganika, "Analisis Kecacatan Produk Sebagai Upaya Perbaikan Kualitas Menuju Zero Defect," Jurnal Manajemen dan Bisnis, Vol. IX, No.1, Hal 121-135, 2016.

[2] S. Masitoh, Y. H. Yadi and A. S. Mariawati, "Analisa Tingkat Keandalan Operator Inside Welding dengan Metode Human Error Assessment and Reduction Technique," Jurnal Online Teknik Industri Universitas Sultan Ageng Tirtayasa, 2013.

[3] T. Pradana and W. A. A. Pradana, "Sistem Informasi Pengendalian Kualitas Untuk Mengetahui Cacat Produk Pipa," Jurnal SPIRIT Teknik Informatika, Vol. 11, No. 1, hal 68 - 72, 2019.

[4] Rendy Kaban, "Pengendalian Kualitas Kemasan Plastik Pouch Menggunakan Statistical Procces Control (SPC) Di Pt Incasi Raya Padang,” Jurnal Optimasi Sistem Industri, Vol.13, No.1, Hal 518-547, 2014.

[5] Purwanto, M. F. Sufa and R. Fitriadi, "Analisis Human Error Operator Mesin Ring Yarn Dengan Metode Human Error Assessment And Reduction Technique ( HEART )," Jurnal Online Teknik Industri Universitas Muhammadiyah Surakarta, 2014.

[6] A. S. Pamuka and N. Susanto, "Human Reliability Assesment Dengan Metode Heart Sebagai Upaya Mengurangi Human Error Pada Pt. Multipanel Intermitra Mandiri," Jurnal Online Teknik Industri Universitas Diponegoro Semarang, 2016.

[7] Y. Widharto, D. Iskandari and D. Nurkertamanda, "Analisis Human Reliability Assessment Dengan Metode HEART STUDI KASUS PT ABC," Jurnal Online Teknik Industri Universitas Diponegoro, Vol.13, No.3, Hal 141-150, 2018.

[8] Maya Masita, "Analisis Human Error Dengan Metode Sherpa Dan Heart Pada Proses Produksi Batik Cap Studi Kasus di UKM Batik Cap Supriyarso Kampoeng Batik Laweyan," Jurnal Online Teknik Industri Universitas Muhammadiyah Surakarta, 2017.

[9] M. F. Sufa, Purwanto and R. Fitriadi, "Analisis Human Error Operator Mesin Ring Yarn Dengan Metode Human Error Assessment And Reduction Technique (Heart)," Jurnal Penelitian Universitas Muhammadiyah Surakarta, Hal 827-834, 2014.

[10] Y. L. W. Astuti and S. Saptadi, ”Usulan Rekomendasi Perbaikan Pada Proses Pengecoran ( Concrete Filling ) Dan Pengeluaran Produk Beton ( De-Moulding ) Berdasarkan Analisa Keandalan Manusia Menggunakan Metode Human Error Asessment And Reduction Technique ( Heart ) Di Pt Wijaya Karya Beton Tbk," Jurnal Online Teknik Industri Universitas Diponegoro, 2017.

[11] Erma Safitri, "Pengaruh Pelatihan Dan Disiplin Kerja Terhadap Kinerja Karyawan,” Jurnal Ilmiah Manajemen Universitas negeri Surabaya, Vol.1, No.4, 2013. 